Review began 11/07/2021 Review ended 11/19/2021 Published 11/26/2021

(c) Copyright 2021

Hali et al. This is an open access article distributed under the terms of the Creative Commons Attribution License CC-BY 4.0. which permits unrestricted use, distribution, and reproduction in any medium, provided the original author and source are credited.

\section{Nail Mycosis Fungoides: A New Case}

Fouzia Hali $^{1}$, Ntihebuwayo Jean Berchmans ${ }^{1}$, Farida Marnissi ${ }^{2}$, El Kebir Asma ${ }^{2}$, Soumiya Chiheb ${ }^{1}$

1. Department of Dermatology, University Hospital Center Ibn Rochd, University Hassan II, Casablanca, MAR 2. Central Pathological Anatomy Laboratory, University Hospital Center Ibn Rochd, University Hassan II, Casablanca, MAR

Corresponding author: Ntihebuwayo Jean Berchmans, ntiheba@gmail.com

Abstract

Ungueotropic mycosis is a rare form of mycosis fungoides. We present the case of a 32-year-old female patient with advanced tumor stage mycosis fungoides, presenting a phanerial involvement with lymphoid infiltration of the nails and scalp confirmed by histology and immunohistochemistry.

Categories: Dermatology, Hematology

Keywords: biopsy of the nail matrix and nail, pilotropic, nail lymphoid infiltration, nail changes, mycosis fungoides

\section{Introduction}

Ungueotropic mycosis is defined as a rare variant of mycosis fungoides (MF) with predominantly nail involvement. Nail changes in primary cutaneous T-cell lymphoma have been rarely described. Nail involvement is seen in mycosis fungoides (MF), usually at an advanced stage, as well as in true Sezary syndrome. Only eight cases of mycosis fungoides with histologically and immunohistochemically confirmed nail involvement have been reported in the literature [1-4].

We report a case of advanced mycosis fungoides with nail involvement and palmar keratosis hands as a starting point.

\section{Case Presentation}

A 32-year-old female patient presented with pruritic palmar keratosis of the hands for two years, followed one year later by the appearance of infiltrated and pruritic patches of skin and onychodystrophy of the fingernails concomitant with diffuse alopecia of the scalp. Examination of the nails showed xanthopachyonychia, trachyonychia, and perionyxis of both thumbs (Figure 1). 


\section{Cureus}

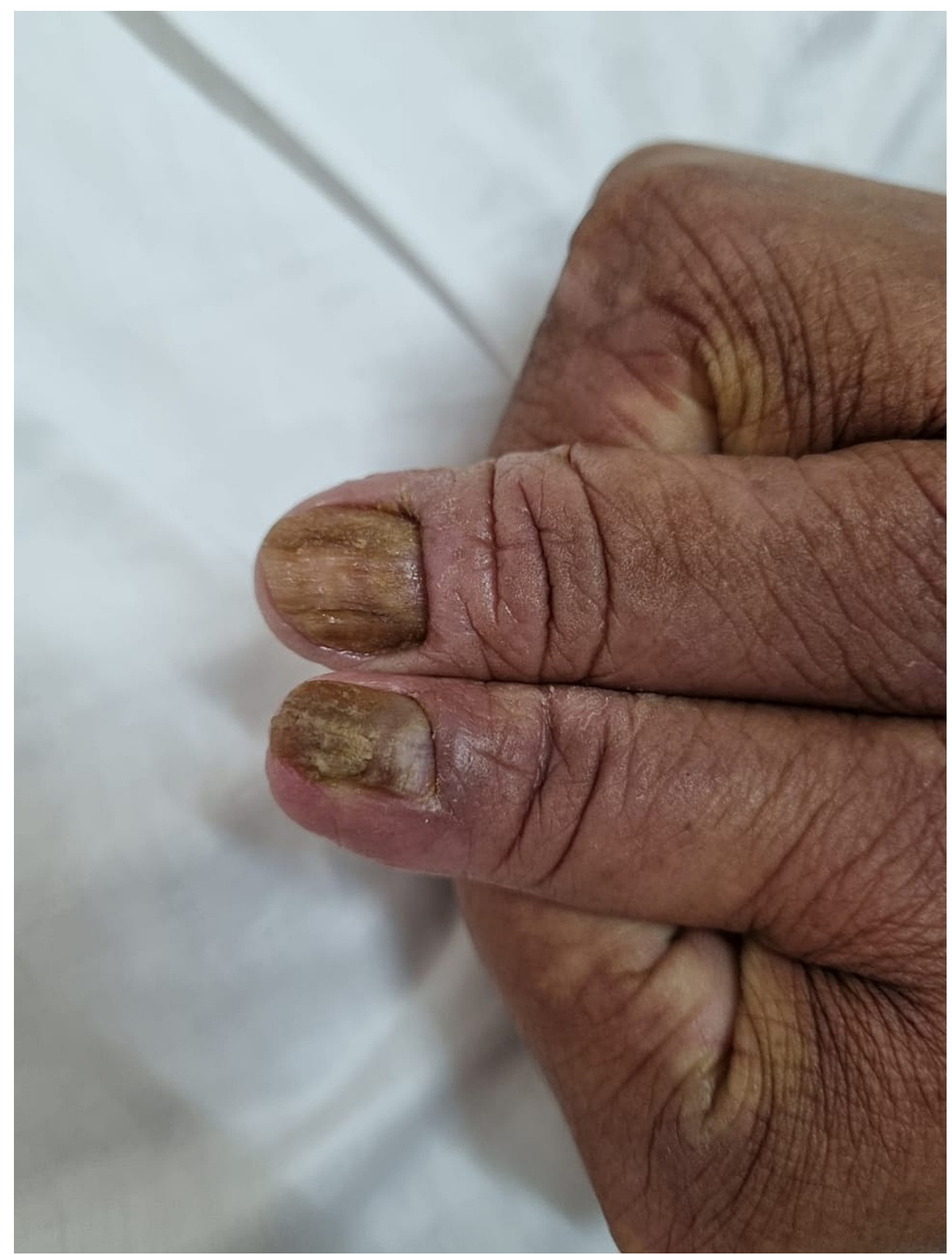

FIGURE 1: Xanthopachyonychia, trachyonychia, and perionyxis of both thumbs.

Trachyonychia and lateroproximal xanthonychia of the right index finger and the left ulnar (Figure 2). 


\section{Cureus}

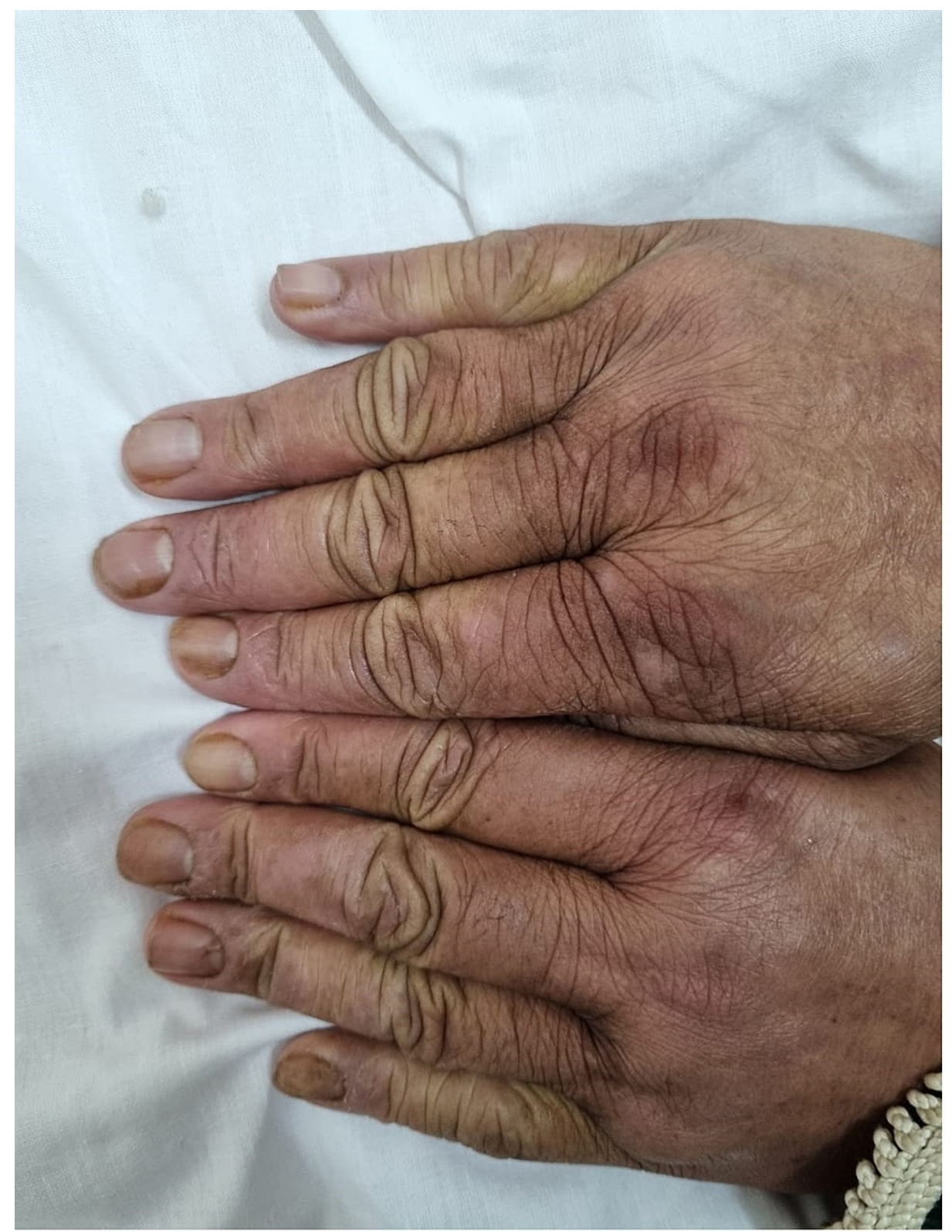

FIGURE 2: Trachyonychia and lateroproximal xanthonychia of the right index finger and the left ulnar.

Histological biopsy of the nail matrix and nail bed showed a banded lymphocytic proliferation with focal epidermotropism. Cell size was small to medium with angular or rounded nuclei, associated with histiocytes (Figure 3). 


\section{Cureus}

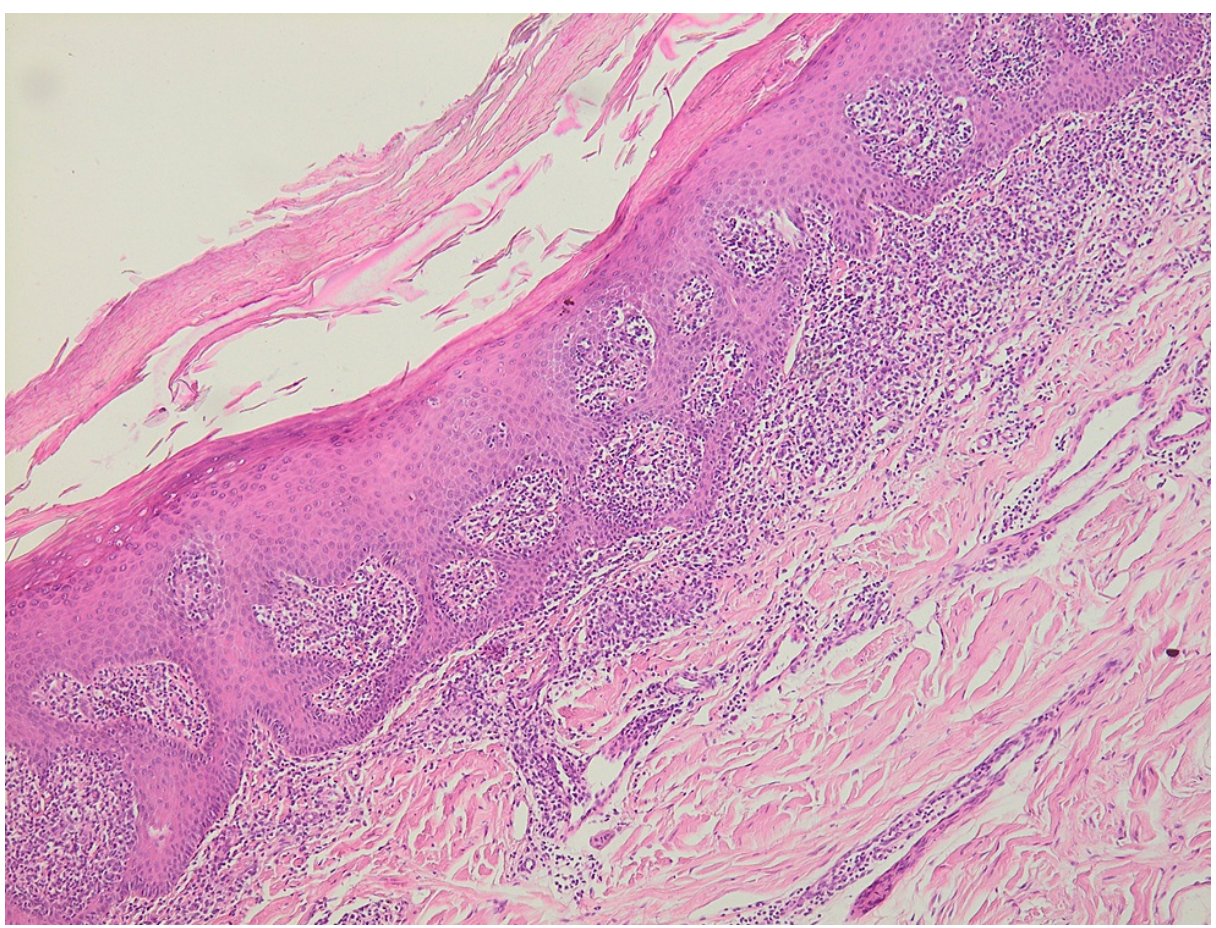

FIGURE 3: Histological biopsy of the nail matrix and nail bed showed a banded lymphocytic proliferation with focal epidermotropism.

Immunohistochemistry showed an atypical lymphocytic infiltrate strongly expressing CD3 and CD4 in a superimposable manner (Figures 4, 5).

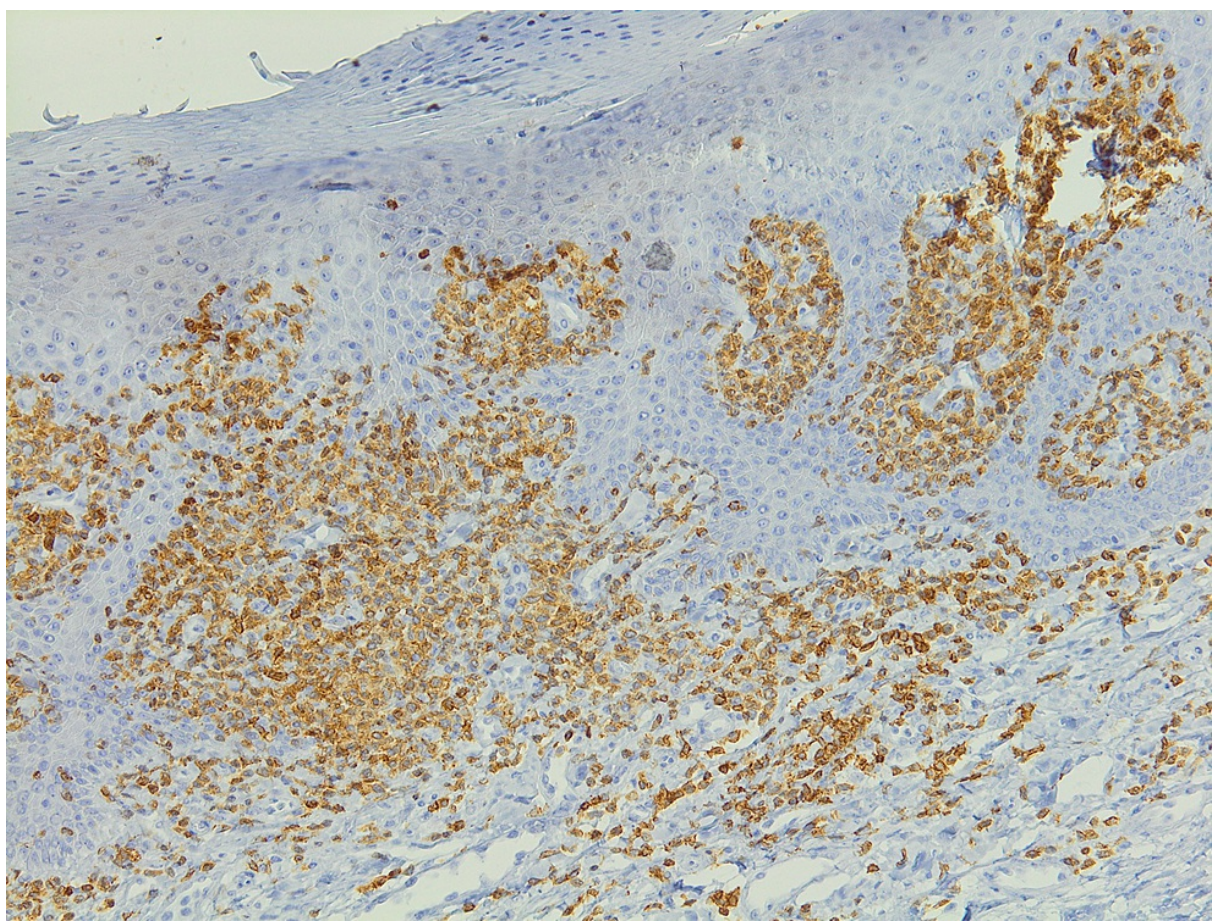

FIGURE 4: Immunohistochemistry showed an atypical lymphocytic infiltrate strongly expressing CD3. 


\section{Cureus}

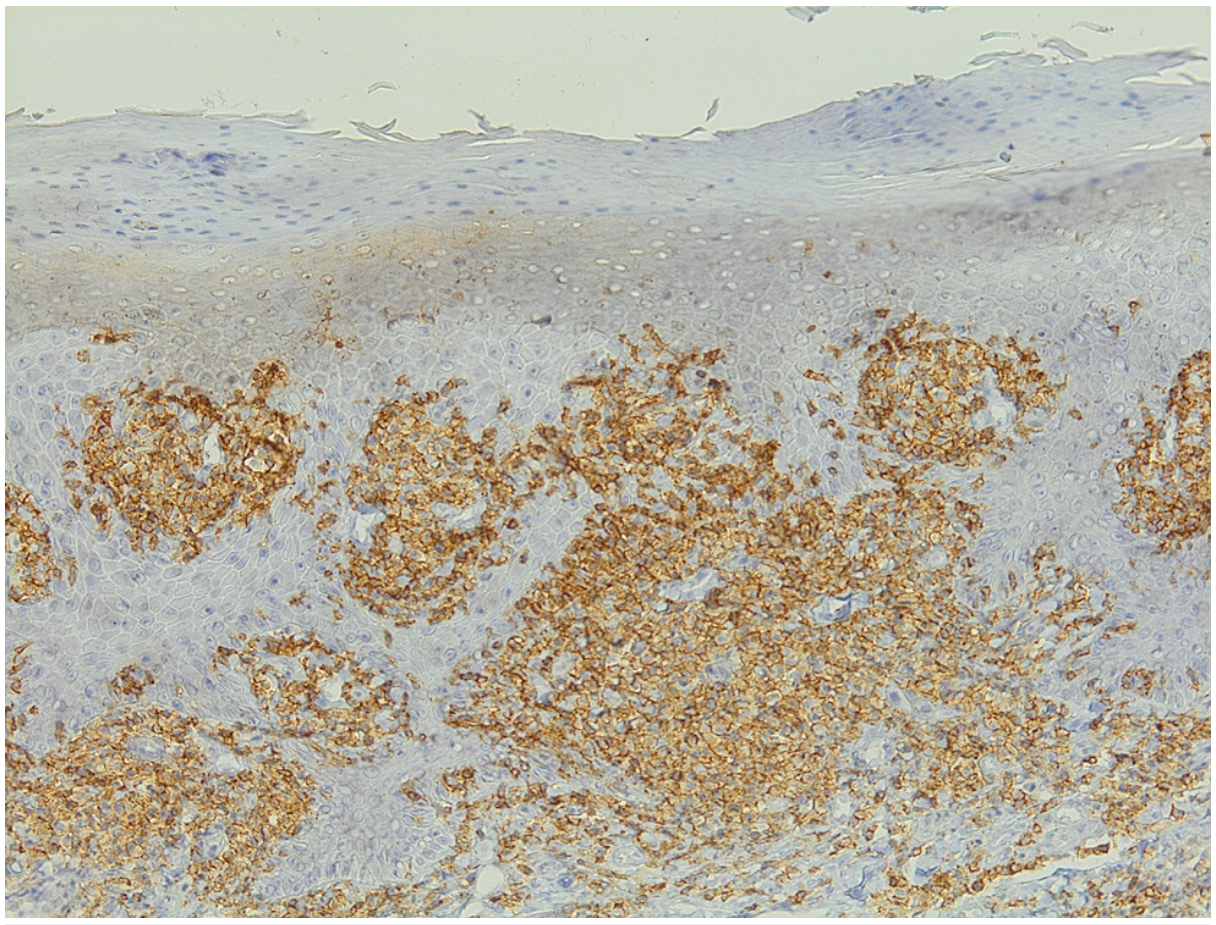

\section{FIGURE 5: Immunohistochemistry showed an atypical lymphocytic infiltrate strongly expressing CD4.}

CD8 was negative. The histological and immunohistochemical conclusion was in favor of a nail mycosis fungoides without signs of transformation. Biopsy of an infiltrated patch of skin, alopecia, and forehead nodule concluded pilotropic mycosis fungoides. Bone marrow biopsy for bone marrow invasion, cervical adenopathy for lymph node involvement, blood smear for sezary cells in the blood were all normal. The biological workup showed eosinophilic leukocytosis up to 20,300 cells $/ \mathrm{m}^{3}$, IgE $307.09 \mathrm{IU} / \mathrm{mL}$, lactate dehydrogenase $467 \mathrm{IU} / \mathrm{L}, \mathrm{C}$-reactive protein $22 \mathrm{mg} / \mathrm{L}$, liver and kidney function within normal limits. CT scans of the lungs, abdomen, and pelvis were normal. A diagnosis of pilotropic mycosis fungoides tumor stage IIB: T3N1M0B0 with nail involvement was made. Pyrimidine analogue and platinum-based antineoplastic chemotherapy were initiated. The evolution was marked by a slight disinfiltration of the plaques and nodules and a slight decrease of the perinonxys with slight improvement of the trachyonychia and xanthonychia of the right index finger and the left ulnar after three courses of chemotherapy.

\section{Discussion}

Mycosis fungoides with histologically and immunohistochemically confirmed nail involvement has been rarely described in the literature $[4,5]$. Its incidence is poorly known, and only eight cases confirmed by nail biopsy have been reported $[1,4,6,7]$. In all published reports, the types and stages of mycosis fungoides varied from case to case. Nail changes ranged from simple yellowish discoloration to slowed growth, nail thickening and increased curvature, and onychomadesis. Previously reported types of mycosis fungoides with nail involvement confirmed by histology and immunohistochemistry included folliculotropic, pilotropic, and palmoplantar mycosis fungoides $[1,8,9]$. Nail involvement has also been observed in advanced-stage mycosis fungoides as well as in true Sézary syndromes [4,6,7,10,11]. Paronychia, trachyonychia, onycholysis, and subungual hyperkeratosis have been described as a direct consequence of folliculotropic mycosis infiltration affecting the nails [7]. Some nail manifestations were considered specific to mycosis fungoides. These included yellowish discoloration of the nails, slow growth, thickening, onycholysis, onychomadesis, subungual hyperkeratosis, and pterygium formation $[4,5]$. The nail changes in mycosis fungoides are thought to be related to the abnormal production of $\mathrm{T}$ cells in the skin, which are responsible for the prolonged growth arrest and general nail impairment, apart from any other factors and diseases that may affect nail growth, morphology, and appearance. Another thesis suggested that the clinical changes of the nails were related either to a non-specific effect of chronic erythroderma as in the case of Sézary syndrome or to an infiltration of T lymphocytes in the nail apparatus [7]. Lichen planus is thought to be one of the precursor dermatoses of mycosis fungoides [7]. To confirm nail involvement in mycosis fungoides, biopsies should include the nail bed and matrix [7-9]. The frequency of nail involvement may be underestimated because skin biopsies showing erythema and scaling around the nail plate with clinically significant nail changes have not revealed any evidence of mycosis fungoides [5]. To our knowledge, we report the first case of mycosis fungoides with nail involvement that presented with concomitant onychodystrophy and diffuse alopecia of the scalp. Treatment of nail involvement in mycosis fungoides is not well codified because of the limited number of cases reported. Treatments have included 
chlorambucil, gemtabicin, puvatherapy, and electron beam radiation therapy with partial responses or complete remissions $[5,7]$.

\section{Conclusions}

Our observation illustrates a rare presentation of histologically and immunohistochemically confirmed nail mycosis fungoides. The coexistence of onychodystrophy and alopecia should be recognized and considered in all patients with suspected mycosis fungoides. Matrix and nail bed biopsy should be routinely offered to confirm nail involvement in mycosis fungoides. Further studies are needed to determine whether the involvement of the dander during cutaneous T-cell lymphoma can provide useful information about disease progression before or during treatment.

\section{Additional Information \\ Disclosures}

Human subjects: Consent was obtained or waived by all participants in this study. Conflicts of interest: In compliance with the ICMJE uniform disclosure form, all authors declare the following: Payment/services info: All authors have declared that no financial support was received from any organization for the submitted work. Financial relationships: All authors have declared that they have no financial relationships at present or within the previous three years with any organizations that might have an interest in the submitted work. Other relationships: All authors have declared that there are no other relationships or activities that could appear to have influenced the submitted work.

\section{References}

1. Harland E, Dalle S, Balme B, Dumontet C, Thomas L: Ungueotropic T-cell lymphoma. Arch Dermatol. 2006, 142:1065-86. 10.1001/archderm.142.8.1071

2. de Masson A, Battistella M, Vignon-Pennamen MD, et al.: Syringotropic mycosis fungoides: clinical and histologic features, response to treatment, and outcome in 19 patients. J Am Acad Dermatol. 2014, 71:92634. 10.1016/j.jaad.2014.06.033

3. Lehman JS, Cook-Norris RH, Weed BR, et al.: Folliculotropic mycosis fungoides: single-center study and systematic review. Arch Dermatol. 2010, 146:607-13. 10.1001/archdermatol.2010.101

4. Parmentier L, Dürr C, Vassella E, Beltraminelli H, Borradori L, Haneke E: Specific nail alterations in cutaneous T-cell lymphoma: successful treatment with topical mechlorethamine. Arch Dermatol. 2010, 146:1287-91. 10.1001/archdermatol.2010.325

5. Ehsani AH, Nasimi M, Azizpour A, Noormohammadpoor P, Kamyab K, Seirafi H, Noori M: Nail changes in early mycosis fungoides. Skin Appendage Disord. 2018, 4:55-9. 10.1159/000478946

6. Tosti A, Fanti PA, Varotti C: Massive lymphomatous nail involvement in Sézary syndrome. Dermatology. 1990, 181:162-4. 10.1159/000247911

7. Mazzurco JD, Schapiro BL, Fivenson DP: Localized mycosis fungoides of the bilateral thumbs and nail units treated with orthovoltage radiation. Int J Dermatol. 2010, 49:1334-5. 10.1111/j.1365-4632.2010.04649.x

8. Dalziel KL, Telfer NR, Dawber RPR: Nail dystrophy in cutaneous T-cell lymphoma. Br J Dermatol. 1989, 120:571-4. 10.1111/j.1365-2133.1989.tb01333.x

9. Toritsugi M, Satoh T, Higuchi T, Yokozeki H, Nishioka K: A vesiculopustular variant of mycosis fungoides palmaris et plantaris masquerading as palmoplantar pustulosis with nail involvement. J Am Acad Dermatol. 2004, 51:139-41. 10.1016/j.jaad.2003.12.011

10. Stosiek N, Peters KP, Hiller D, Riedl B, Hornstein OP: Yellow nail syndrome in a patient with mycosis fungoides. J Am Acad Dermatol. 1993, 28:792-4.

11. Grande-Sarpa H, Callis Duffin KP, Florell SR: Onychodystrophy and tumor-stage mycosis fungoides confined to a single digit: report of a case and review of nail findings in cutaneous T-cell lymphoma. J Am Acad Dermatol. 2008, 59:154-7. 10.1016/j.jaad.2008.03.037 